\title{
Acoustic Emission Parameters of Three Gorges Sandstone during Shear Failure
}

\author{
Jiang XU, Yixin LIU, and Shoujian PENG \\ State Key Laboratory of Coal Mine Disaster Dynamics and Control, \\ Chongqing University, Chongqing, China \\ State and Local Joint Engineering Laboratory \\ of Methane Drainage in Complex Coal Gas Seam, \\ Chongqing University, Chongqing, China \\ e-mails: jiangxu@cqu.edu.cn, yxliu@cqu.edu.cn (corresponding author), \\ sjpeng@cqu.edu.cn
}

\begin{abstract}
In this paper, an experimental investigation of sandstone samples from the Three Gorges during shear failure was conducted using acoustic emission (AE) and direct shear tests. The AE count rate, cumulative $\mathrm{AE}$ count, AE energy, and amplitude of the sandstone samples were determined. Then, the relationships among the AE signals and shearing behaviors of the samples were analyzed in order to detect micro-crack initiation and propagation and reflect shear failure. The results indicated that both the shear strength and displacement exhibited a logarithmic relationship with the displacement rate at peak levels of stress. In addition, the various characteristics of the AE signals were apparent in various situations. The AE signals corresponded with the shear stress under different displacement rates. As the displacement rate increased, the amount of accumulative damage to each specimen decreased, while the AE energy peaked earlier and more significantly. The cumulative AE count primarily increased during the post-peak period. Furthermore, the AE count rate and amplitude exhibited two peaks during the peak shear stress
\end{abstract}

Ownership: Institute of Geophysics, Polish Academy of Sciences;

(C) $2016 \mathrm{Xu}$ et al. This is an open access article distributed under the Creative Commons Attribution-NonCommercial-NoDerivs license, http://creativecommons.org/licenses/by-nc-nd/3.0/. 
period due to crack coalescence and rock bridge breakage. These isolated cracks later formed larger fractures and eventually caused ruptures.

Key words: sandstone, shear failure, acoustic emission, displacement rate.

\section{INTRODUCTION}

Rock slope stability estimations are required for a variety of civil, road and mining engineering projects not only in feasibility studies, but also in the excavation and operating stages (Taheri and Tani 2010). In these projects, numerous tunnels and caverns are created through brittle rock mass under high amounts of stress. Under these stressful conditions, rock structures become less stable, ultimately resulting in rock failure (Chang and Lee 2004, Stock et al. 2012). Previous studies concerning the behaviors of rock under various strain rates have shown that the compressive strength, Young's Modulus, and Poisson's Ratio of rock are highly dependent upon the strain rate (Kawamato and Saito 1974, Kranz 1979, Lajtai et al. 1991). However, a more detailed study of the mechanical behaviors of rock could provide valuable information regarding rock structure design as well as numerous mining operations, such as drilling, blasting, and crushing. Strain levels can change within seconds during blasting and earthquakes, or over many years during mining operations (Ray et al. 1999). Rock is a typical inhomogenous and anisotropic material that contains several natural defects with various scales, such as micro cracks, pores, joint inclusions, and precipitates. A large number of acoustic emission (AE) events occur when rock specimens are subjected to loading stages until failure. AE signals are associated with the initiation and propagation of micro-cracks, and provide a significant amount of information regarding the internal structural changes that occur in rock. Therefore, the behaviors of rock are reflected by their AE signals (Li et al. 2010, Lockner 1993, Katsuyama 1996).

Numerous studies concerning the acoustic emissions of rock have been published. Moradian et al. (2010) investigated the AE signal characteristics of various joints and concluded that $\mathrm{AE}$ signals could be used to effectively monitor the shear behaviors of joints. Chang and Lee (2004) investigated the fracture and damage mechanisms induced by micro-crack accumulation in rocks by conducting a moment tensor analysis and applying the moving point regression technique to acoustic emission (AE) and strain data obtained via triaxial compression tests. Xu et al. (2009) used the acoustic emission (AE) technique to continuously monitor micro-crack development and failure in rock samples in real-time. Majewska and Mortimer (2006) studied non-linear dynamics of acoustic emission (AE) generated in coal samples subjected to gas sorption-desorption. According to the results, the acoustic 
emission (AE) signal characteristics of the coal rocks accurately reflected their behaviors under different conditions. In the past few decades, many other studies concerning the mechanical behaviors of rocks have been conducted using acoustic emission location technology (Yang et al. 2012, Goszczyńska et al. 2012, Rao and Kusunose 1995).

However, the methods currently used to reflect rock failure using $\mathrm{AE}$ technology are based on the analysis of AE signal characteristics. In this paper, laboratory direct shear tests were conducted under constant normal loading conditions using various shear displacement rates and $\mathrm{AE}$ signals with different characteristics. The parameters included the AE count rate, cumulative AE count, AE energy, and amplitude. The AE signal most representative of the failure process was determined based on the relationships among the $\mathrm{AE}$ signals and shear failure characteristics.

\section{ROCK SAMPLES AND EXPERIMENTAL TECHNIQUES}

\subsection{Rock samples}

The sandstone samples were obtained from the Three Gorges region in ChongQing, China. The samples were primarily composed of quartz, feldspar, chert, and muscovite with a grain size distribution of 0.1 to $0.5 \mathrm{~mm}$. Drilling cores without obvious fractures were selected and cut into cubes with dimensions of approximately $40 \times 40 \times 40 \mathrm{~mm}$. Then, the surfaces of the samples were ground in order to ensure the flatness, verticality, and parallelism standards provided by ISRM. Mesh sandpaper (600, 800, 1200, and 2000 grit) was used to further grind the surfaces in order to ensure a parallelism error of less than $0.02 \mathrm{~mm}$. Five specimens were adopted in laboratory experiments of each conditions, and one typical specimen of each condition was chosen to display and detailed analysis. The Young's modulus is $11.89 \mathrm{GPa}$, the Poisson ratio is 0.37 , the uniaxial compressive strength is $55.97 \mathrm{MPa}$, the density is $2.33 \mathrm{~g} \cdot \mathrm{cm}^{-3}$.

\subsection{Experimental apparatus}

Direct shear tests were performed on the rock specimens under different shear displacement rates using a direct shear apparatus (Fig. 1a). The apparatus consisted of a loading system and acoustic emission monitoring system. A more detailed description of the direct shear apparatus is provided by $\mathrm{Xu}$ et al. (2011).

In displacement rate loading, unlike stress loading, the applied load can be controlled and reduced to a value lower than the peak shear strength. This feature allows for the modelling of the strain-softening behaviors of rock. Thus, constant displacement rates were used to control the loading during the direct shear tests. The control system of the apparatus, which was entire- 

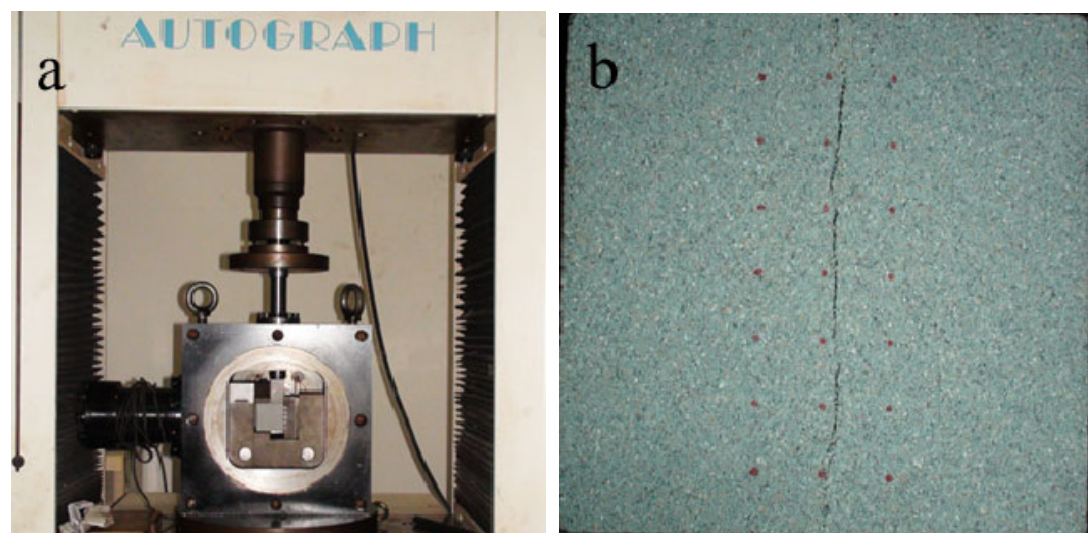

Fig. 1: (a) The direct shear apparatus, and (b) fractured rock sample after the experiment.

ly digital, performed consistently and exhibited a high loading rate accuracy. The loading process stopped automatically once the specimens were broken. The real-time AE signals were acquired using a PCI-2 acoustic emission system. A transducer frequency range of $20 \sim 400 \mathrm{kHz}$ and sampling frequency of $1 \mathrm{MHz}$ were used for the purposes of this study. In addition, a threshold of $40 \mathrm{~dB}$ was used in order to achieve a high signal/noise ratio. The $\mathrm{AE}$ count rate, cumulative $\mathrm{AE}$ count, $\mathrm{AE}$ energy, and amplitude were used as the acoustic emission parameters.

\subsection{Experimental procedure}

Constant displacement rates of $0.200,0.020$, and $0.002 \mathrm{~mm} / \mathrm{min}$ were adopted during the experiments in order to determine the acoustic emission characteristics of the sandstone samples under various shear strain rates. The experiments were conducted on five specimens under different conditions. A specimen representative of each experimental condition was selected and analyzed in detail. In order to ensure synchronization during data acquisition, the loading system and acoustic emission system were initiated simultaneously. The length, width, and height, and other basic parameters of the samples were measured before the experiment. When installed the acoustic emission transducer on the back surface close to the pre shear failure surface, we first spread the face detection with butter and clung to the specimen (as shown in Fig. 2), at the same time fixing the transducer on the specimen with tape to avert the influence caused by transducer off. Figure $1 \mathrm{~b}$ shows the fractured rock sample after the experiment. 


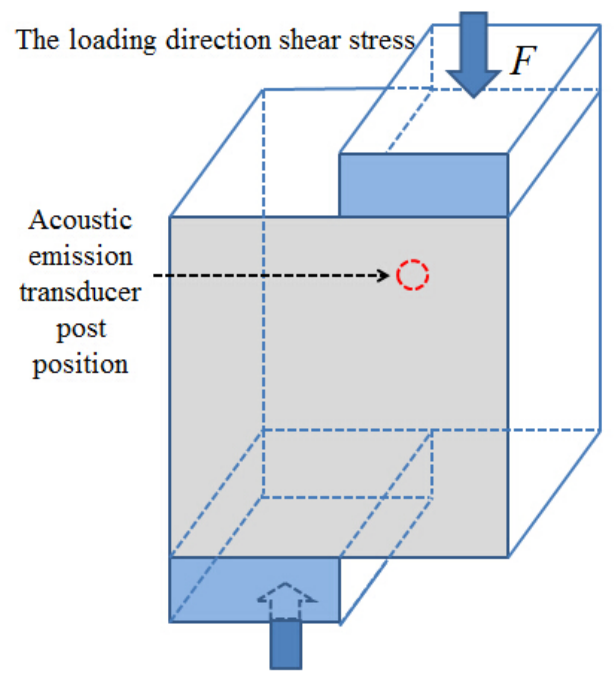

Fig. 2. Acoustic emission transducer paste position.

\section{RESULTS}

\subsection{Deformation characteristics}

Figure 3 displays the shear stress values of the specimens under different displacement rates. As shown in this figure, as the shear displacement rate increased, the shear stress also increased with no apparent periodical characteristics. This was likely because plastic deformation occurs at a more consistent rate during slow straining than during rapid loading (Lavrov 2001). The shear strength of the sandstone also increased with the displacement rate. Table 1 displays the shear strength of the sandstone samples under different displacement rates. Figures $4 \mathrm{a}$ and $\mathrm{b}$ display the relationships between the displacement rates and shear strength and displacement, respectively. As the displacement rate increased, both the shear strength and displacement decreased linearly. These results corresponded with those obtained by $\mathrm{Li}$ et al. (2010) and Zhukov (1965).

Shear strength and displacement of the samples under different displacement rates

\begin{tabular}{|c|c|c|c|}
\hline$V[\mathrm{~mm} / \mathrm{min}]$ & $-\lg V$ & $\tau_{\max }[\mathrm{MPa}]$ & $S[\mathrm{~mm}]$ \\
\hline 0.002 & 2.700 & 14.460 & 0.477 \\
0.020 & 1.700 & 13.398 & 0.447 \\
0.200 & 0.700 & 11.718 & 0.346 \\
\hline
\end{tabular}




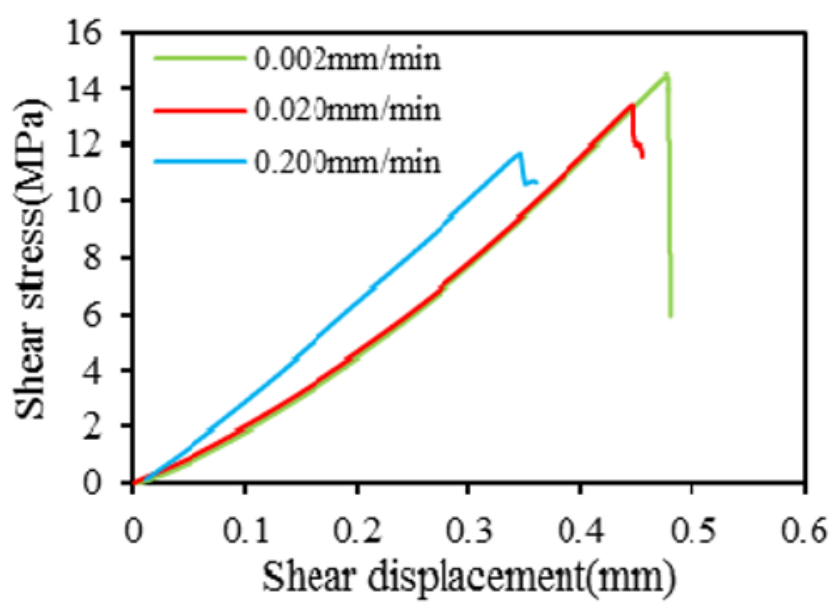

Fig. 3. Shear stress values of the samples under different displacement rates.

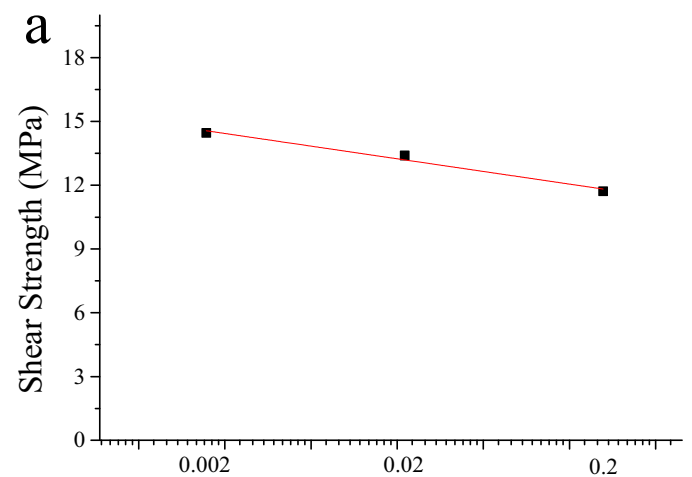

Displacement Rate $(\mathrm{mm} / \mathrm{min})$

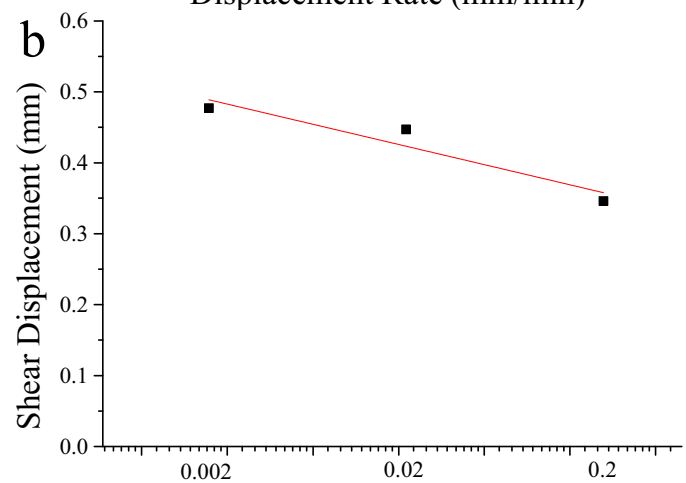

Displacement Rate ( $\mathrm{mm} / \mathrm{min})$

Fig. 4: (a) Displacement rate versus shear stress, and (b) displacement rate versus shear displacement. 


\subsection{AE count rate with time evolution characteristics}

$\mathrm{AE}$ count rate can be used to identify internal transient damage, such as crack initiation and propagation. Figures 5a-c display the relationship between the AE count rate and shear stress under different displacement rates over time. The first acoustic emissions occurred at shear strength values of $0.39 \tau_{\max }, 0.47 \tau_{\max }$, and $0.50 \tau_{\max }$, where $\tau_{\max }$ represents the peak shear stress, or shear strength. Thus, as the displacement rate increased, the amount of shear stress required for micro-crack initiation also increased. As shown in these figures, the displacement rate began to increase as the shear stress peaked, then rapidly decreased. In addition, the AE count rate peaked as the shear stress decreased and peaked earlier than the shear stress at higher displacement rates.

(a)
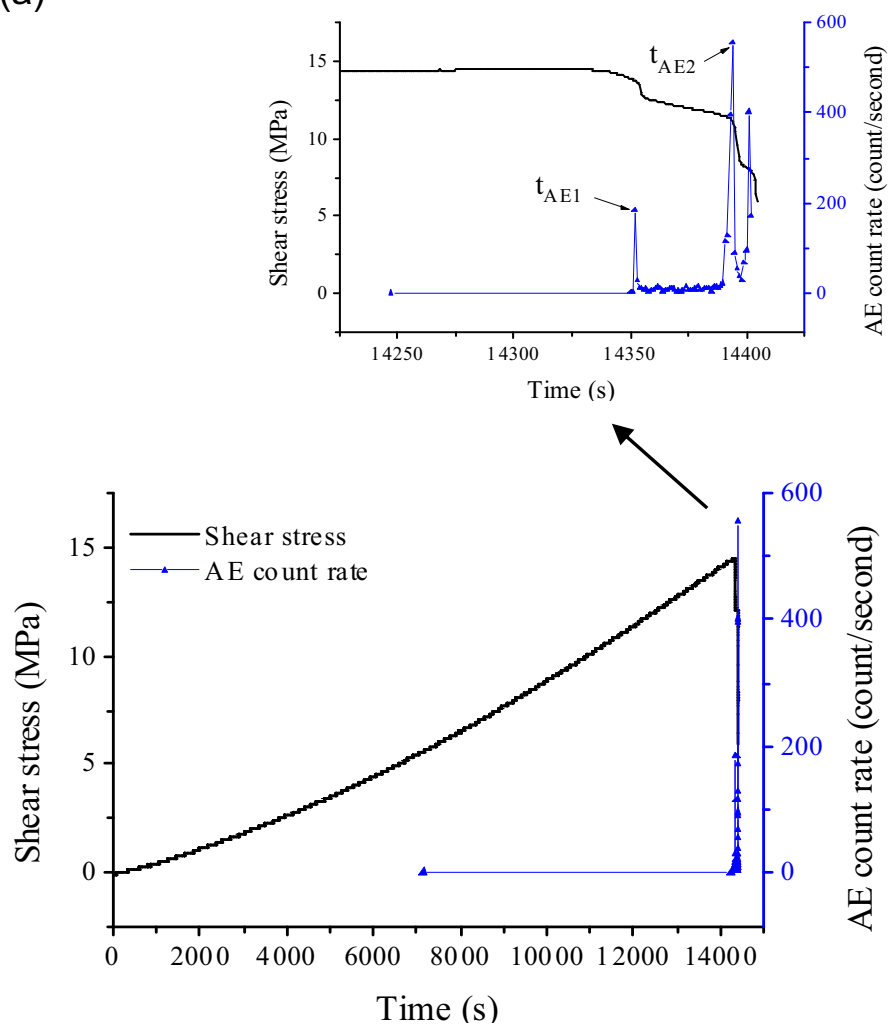

Fig. 5. Caption on next page. 
(b)
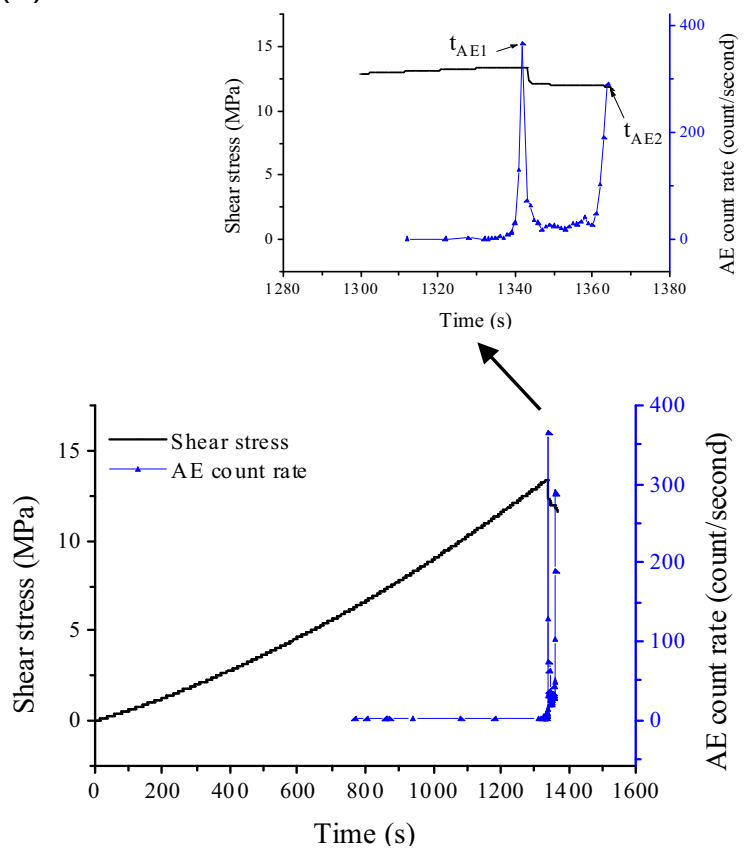

(c)
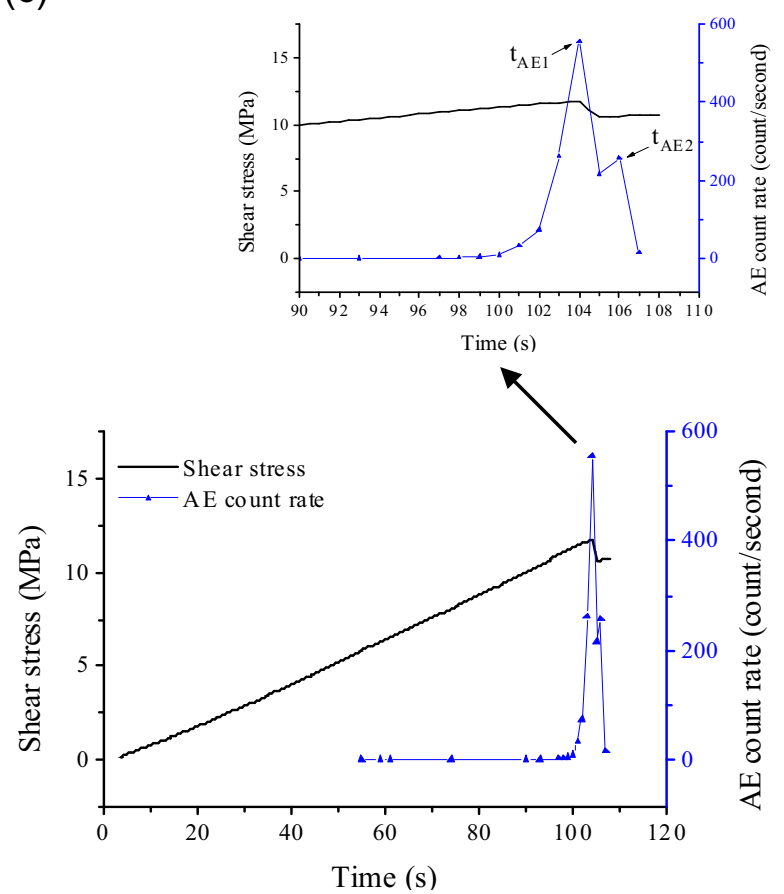

Fig. 5. Shear stress versus $\mathrm{AE}$ count rate under different displacement rates over time: (a) $0.002 \mathrm{~mm} /$ min, (b) $0.02 \mathrm{~mm} / \mathrm{min}$, and (c) $0.2 \mathrm{~mm} / \mathrm{min}$. 


\subsection{Time evolution characteristics of the cumulative AE count}

In this study, the cumulative AE count was used to reflect the internal damage to the sandstone specimens under shear loading. As shown in Figs. 6a-c, the $\mathrm{AE}$ count rate varied as the cumulative AE count periodically increased. The AE counts predominantly occurred during the slowing stage, suggesting that the cracks within the sandstone specimens primarily occurred during this time period. Figure $6 \mathrm{~d}$ displays the cumulative AE counts under the different displacement rates. This result demonstrates that with the increase of displacement rate, the cumulative AE count decreased.

\subsection{Time evolution characteristics of AE Energy}

AE energy represents the amount of elastic energy released as a result of crack initiation and propagation over time. Figures $7 \mathrm{a}-\mathrm{c}$ display the relationship between the AE energy and shear stress under different displacement rates over time. As shown in these figures, as the displacement rate increased, the AE energy began to increase earlier in time. In addition, the $\mathrm{AE}$ energy peaked before the shear stress at a displacement rate of $0.200 \mathrm{~mm} / \mathrm{min}$. These results indicated that fewer micro-cracks propagated as the displacement rate increased, resulting in the accumulation of elastic energy. This elastic energy was released earlier in time at a relatively high rate. In contrast, the AE count rate only peaked once as the shear stress increased. Thus, during shear failure, only a large amount of elastic energy was released, resulting in the rough formation of a single, large crack. Figure $7 \mathrm{~d}$ displays the time evolution curve of the AE energy under different displacement rates. As shown in this figure, the AE energy increased as the displacement rate increased.

\subsection{Time evolution characteristics of the amplitude}

Amplitude, which reflects the size of acoustic emission events, is used to evaluate the sources and magnitude of acoustic emissions. As shown in Figs. 8a-c, the acoustic emission signals exhibited low amplitude values during the pre-peak period. As each acoustic emission signal peaked, the amplitude increased significantly. Sandstone is composed of conglomerated particles. The cracks that occurred in the samples primarily occurred along these grains. Thus, low cement strength was associated with weak AE signals. During peak periods of stress, the shear stress increased, resulting in the propagation of micro-cracks throughout the particles. The formation of these cracks resulted in the rupture of particles and, thereby, the release of strong acoustic emission signals. The amplitude exhibited two peaks, which were determined based on the shear stress values. 
(a)
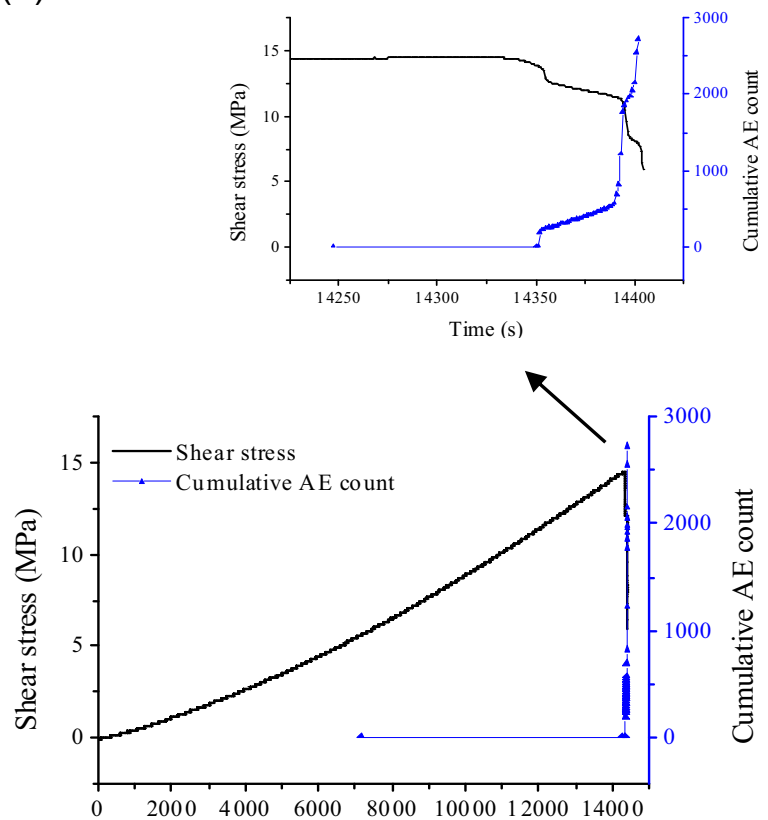

Time (s)

(b)
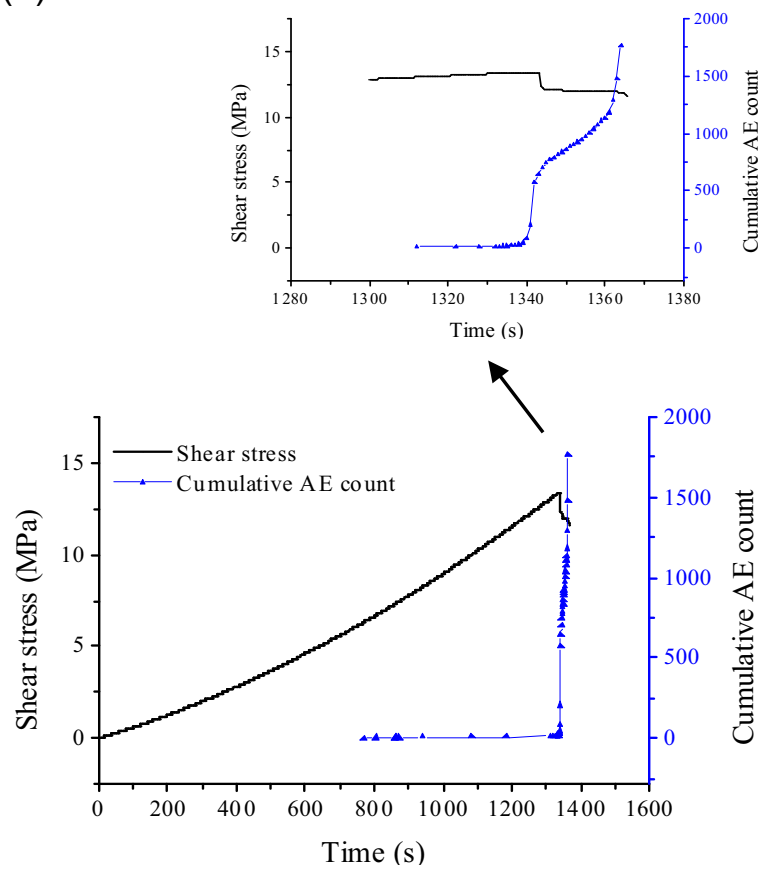

Fig. 6. Caption on next page. 
(c)
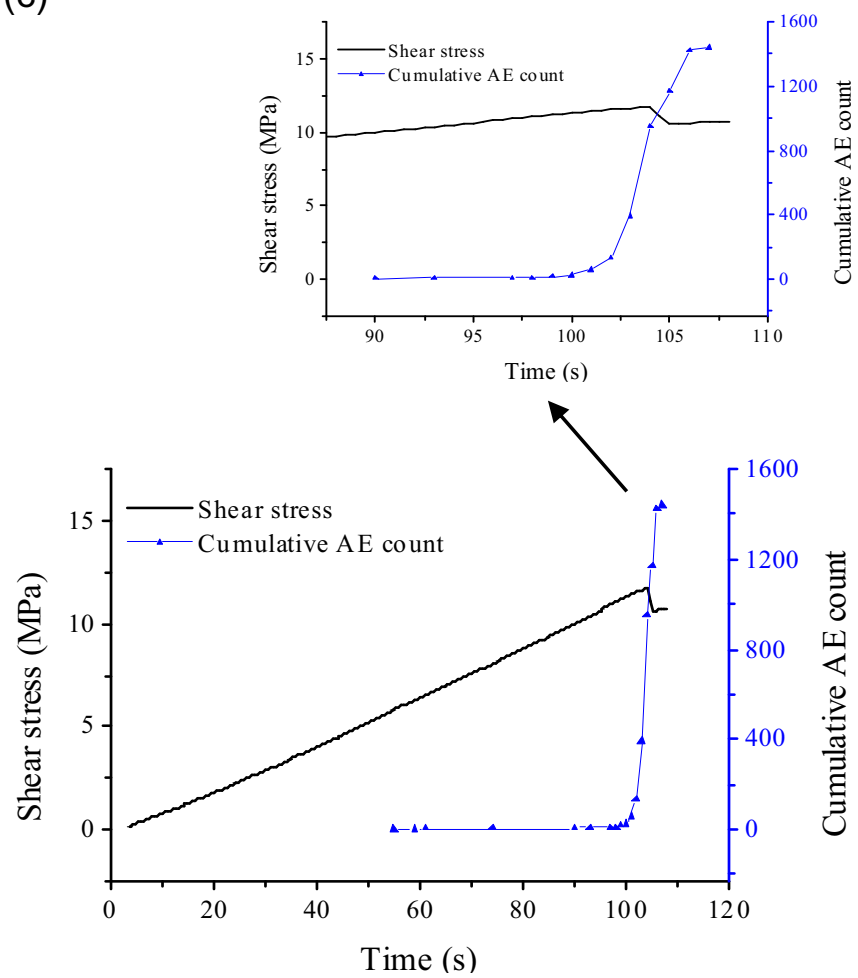

(d)

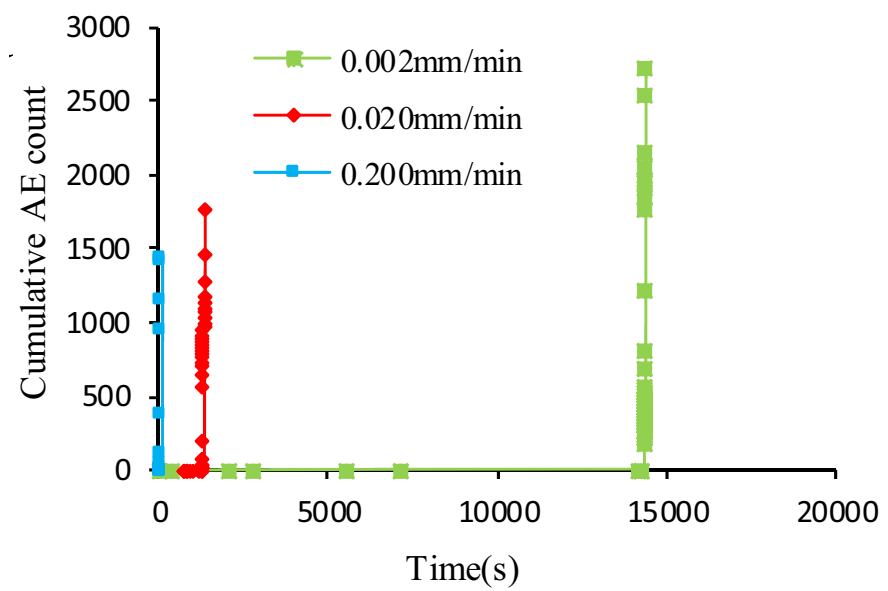

Fig. 6. Shear stress versus cumulative AE count under different displacement rates over time: (a) $0.002 \mathrm{~mm} / \mathrm{min}$, (b) $0.02 \mathrm{~mm} / \mathrm{min}$, (c) $0.2 \mathrm{~mm} / \mathrm{min}$, and (d) contrast curve. 
(a)
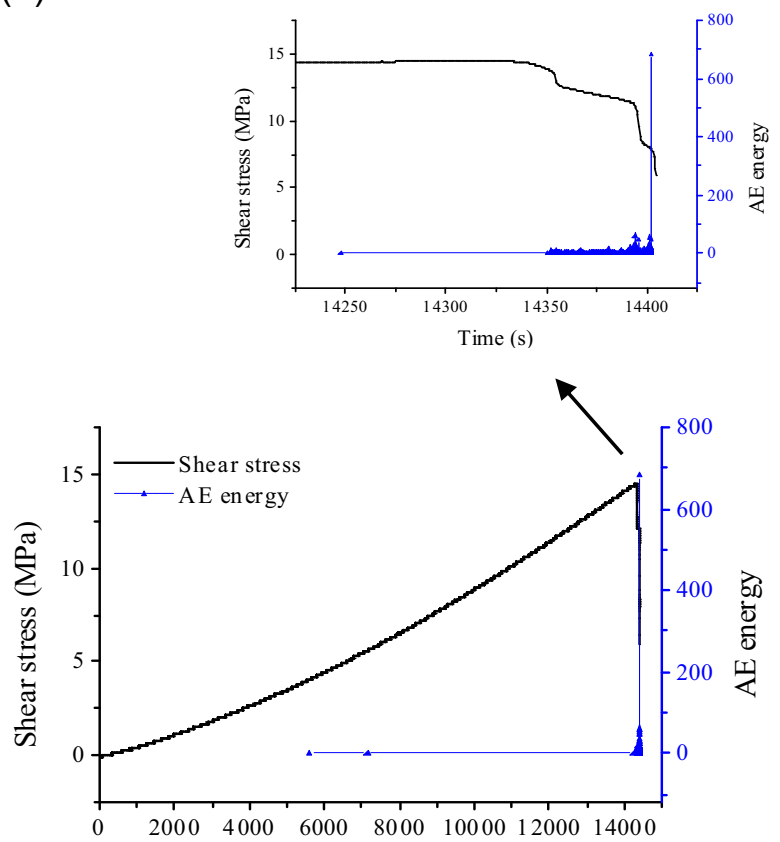

(b)

Time (s)
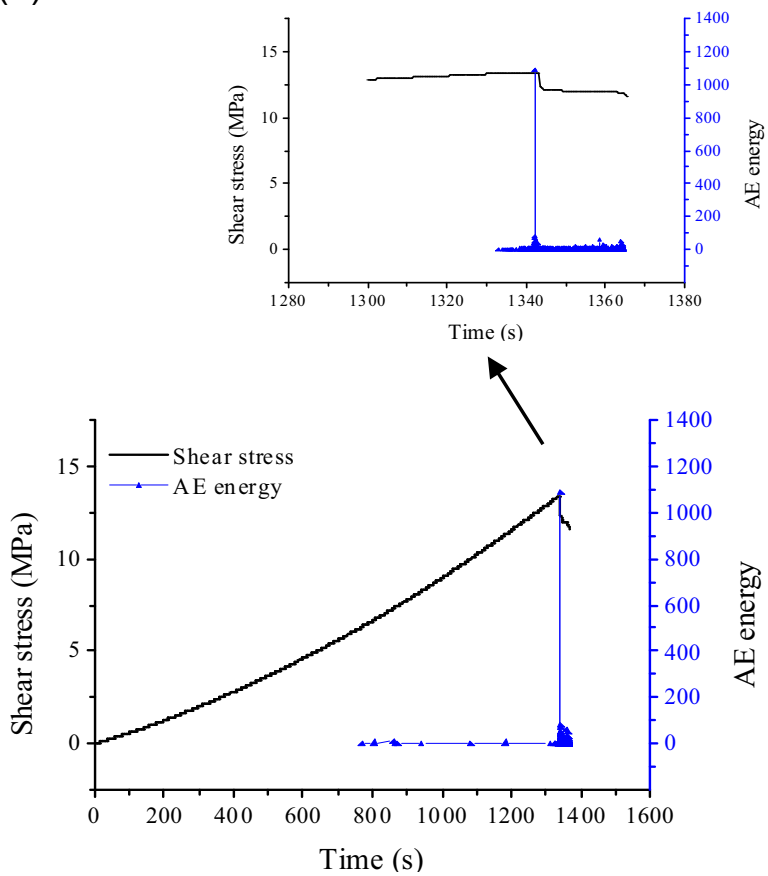

Fig. 7. Caption on next page. 
(c)
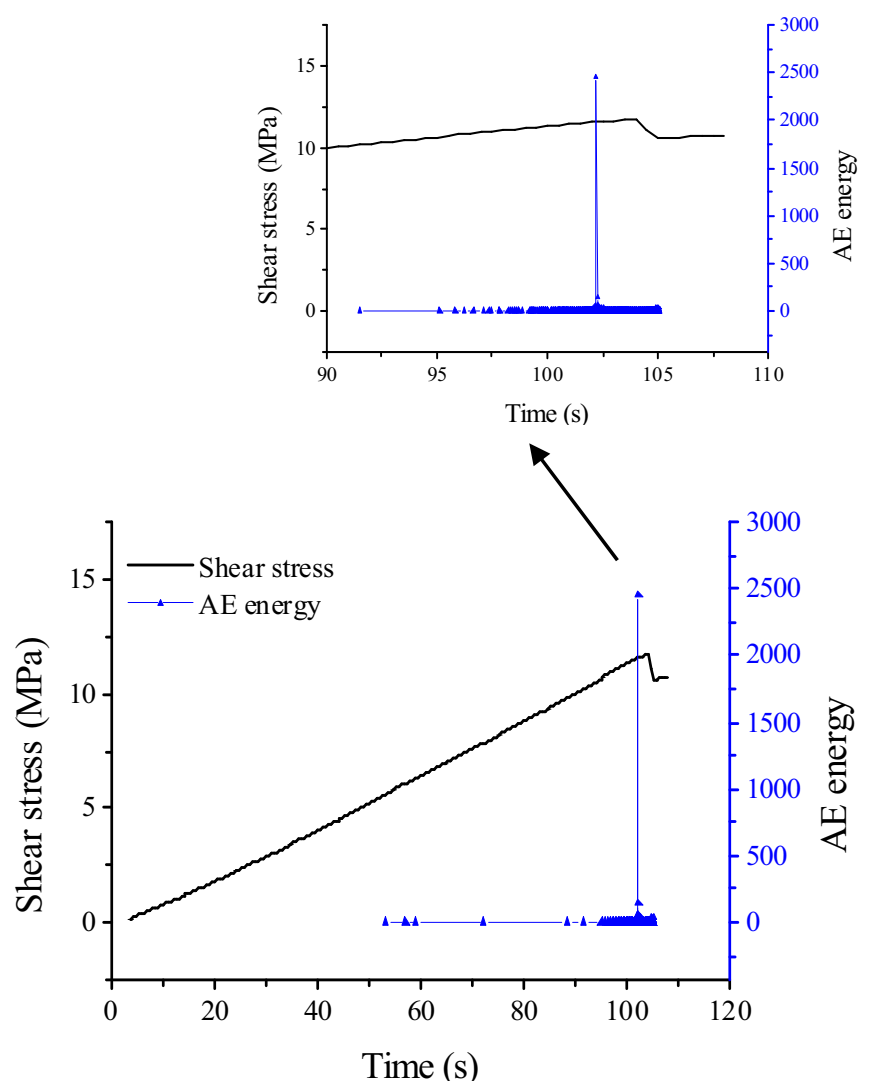

(d)

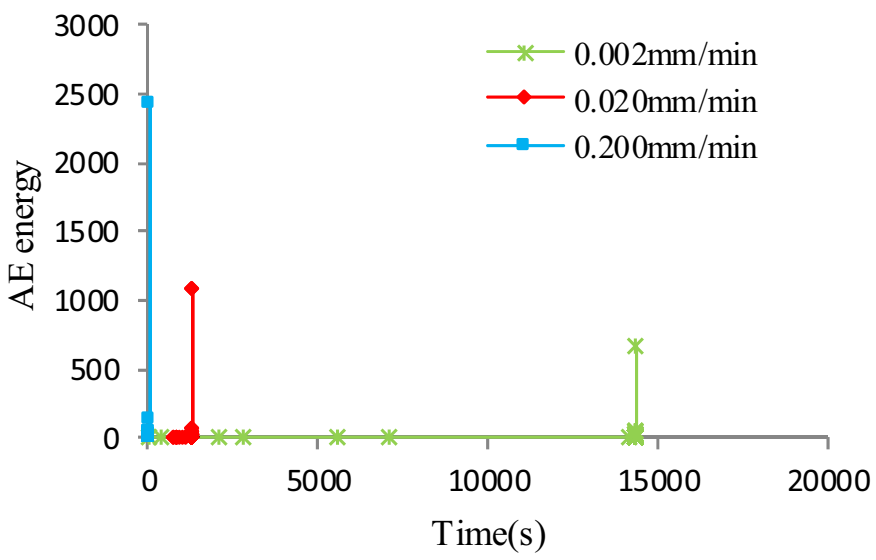

Fig. 7. Shear stress versus $\mathrm{AE}$ energy under different displacement rates over time: (a) $0.002 \mathrm{~mm} / \mathrm{min}$, (b) $0.02 \mathrm{~mm} / \mathrm{min}$, (c) $0.2 \mathrm{~mm} / \mathrm{min}$, and (d) contrast curve. 
(a)
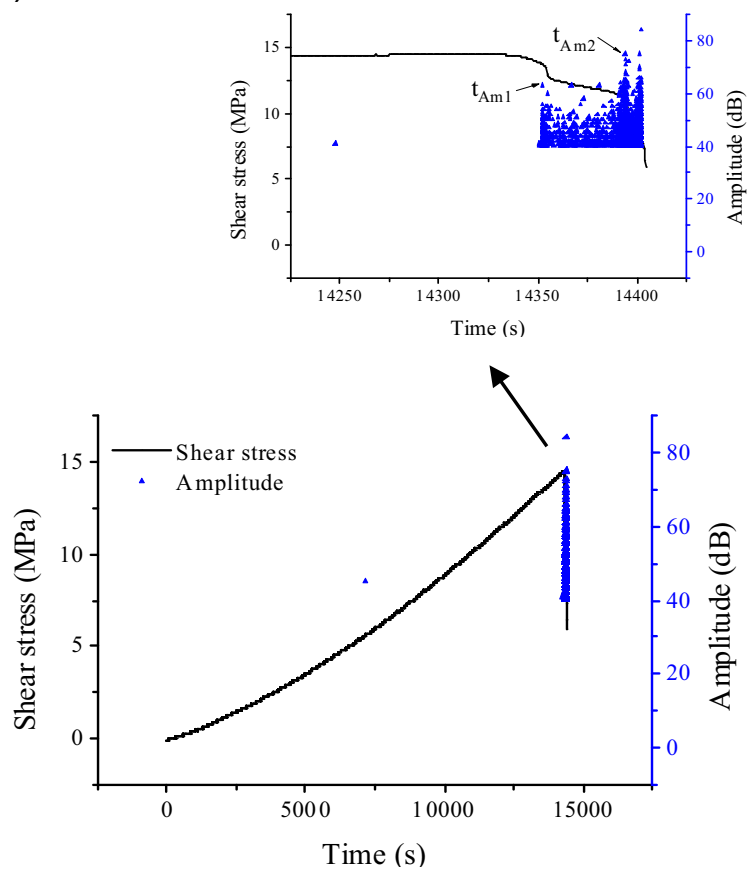

(b)

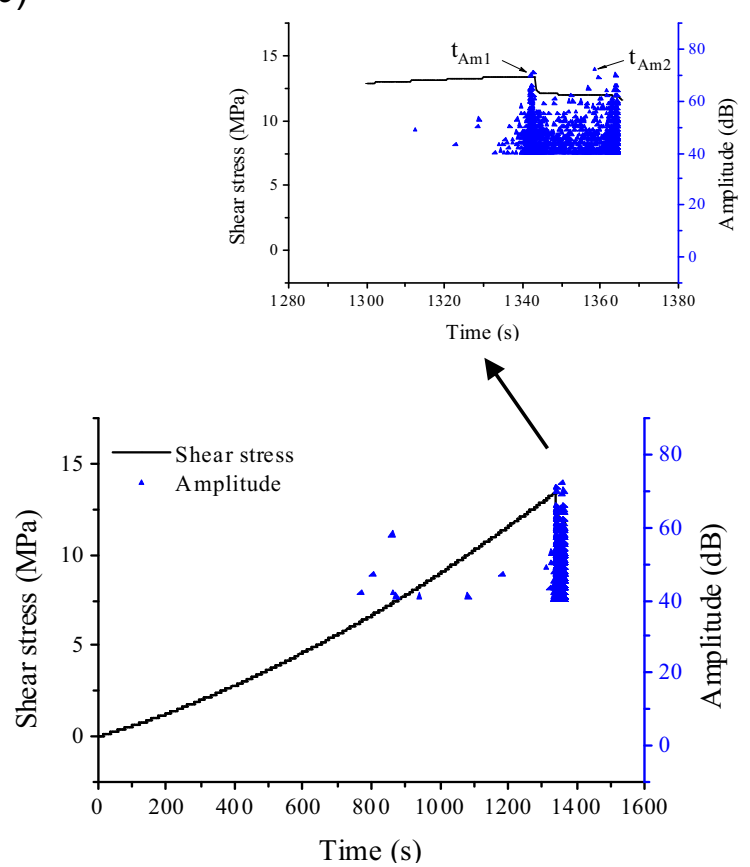

Fig. 8. Caption on next page. 
(c)

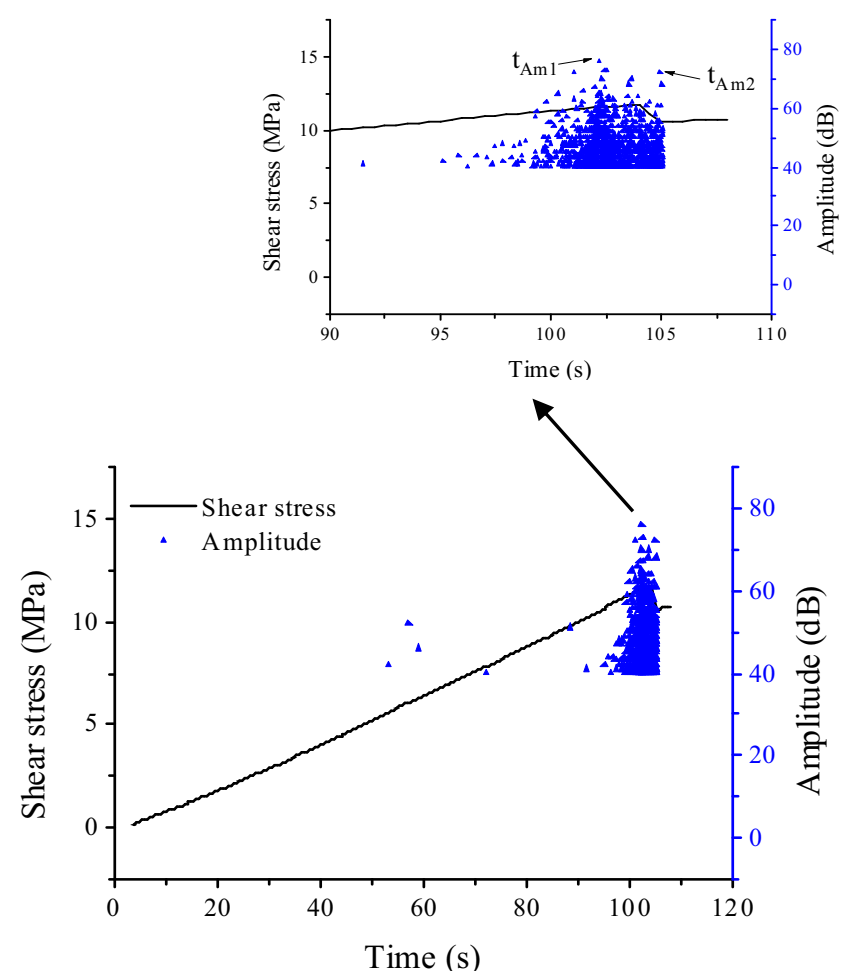

Fig. 8. Shear stress and amplitude versus displacement rate over time: (a) $0.002 \mathrm{~mm} / \mathrm{min}$, (b) $0.02 \mathrm{~mm} / \mathrm{min}$, and (c) $0.2 \mathrm{~mm} / \mathrm{min}$.

\section{DISSCUSION}

Under shear loading, internal stress redistributions in sandstone inevitably result in concentrated stress and, thereby, micro-crack initiation and propagation accompanied by the release of energy. Thus, internal damage can be analyzed based on the elastic waves received by acoustic emission transducers. Elastic waves are caused by the release of energy. In practical engineering applications, monitoring the stress that occurs in rocks as a result of routine operations is difficult. However, rock instability and failure could be reflected by monitoring these changes in acoustic emission signals. Table 2 displays the relationship between the AE signal peak time and specimen fracture time. As shown in this table, as the displacement rate decreased, the amount of time between the first AE signal peak and fracture increased. In addition, the second AE signal peak was more closely correlated with the time of fracture. This second AE signal peak could be used to identify specimen failure. However, in practical engineering applications, failure 
Table 2

Acoustic emission signal peak times and specimen fracture times

\begin{tabular}{|c|c|c|c|c|c|c|}
\hline $\begin{array}{c}V \\
{[\mathrm{~mm} / \mathrm{min}]}\end{array}$ & $\begin{array}{c}t_{\mathrm{C}} \\
{[\mathrm{s}]}\end{array}$ & $\begin{array}{c}t_{\mathrm{AE} 1} / t_{\mathrm{C}-} t_{\mathrm{AE} 1}[\mathrm{~s}] \\
0.002\end{array}$ & $\begin{array}{c}t_{\mathrm{AE} 2} / t_{\mathrm{C}-} t_{\mathrm{AE} 2} \\
{[\mathrm{~s}]}\end{array}$ & $\begin{array}{c}t_{\mathrm{Am} 1} / t_{\mathrm{C}-} t_{\mathrm{Am} 1} \\
{[\mathrm{~s}]}\end{array}$ & $\begin{array}{c}t_{\mathrm{Am} 2} / t_{\mathrm{C}-} t_{\mathrm{Am} 2} \\
{[\mathrm{~s}]}\end{array}$ & $\begin{array}{c}t_{\mathrm{E}} / t_{\mathrm{C}-} t_{\mathrm{E}} \\
{[\mathrm{s}]}\end{array}$ \\
\hline 0.020 & 1363 & $14352 /+49$ & $14394 /+7$ & $14352 /+49$ & $14402 /-1$ & $14402 /-1$ \\
0.200 & 107 & $1342 /+21$ & $1364 /-1$ & $1342 /+21$ & $1358 /+5$ & $1342 /+21$ \\
\hline
\end{tabular}

Notes: $t_{\mathrm{AE} 1}$ denotes the first $\mathrm{AE}$ count rate peak, $t_{\mathrm{AE} 2}$ denotes the second $\mathrm{AE}$ count rate peak, $t_{\mathrm{Am} 1}$ denotes the first amplitude peak, $t_{\mathrm{Am} 2}$ denotes the second amplitude peak, $t_{\mathrm{E}}$ denotes the $\mathrm{AE}$ energy peak, $t_{\mathrm{C}}$ denotes the fracture time, + denotes values earlier than the fracture time, and - denotes values later than the fracture time.

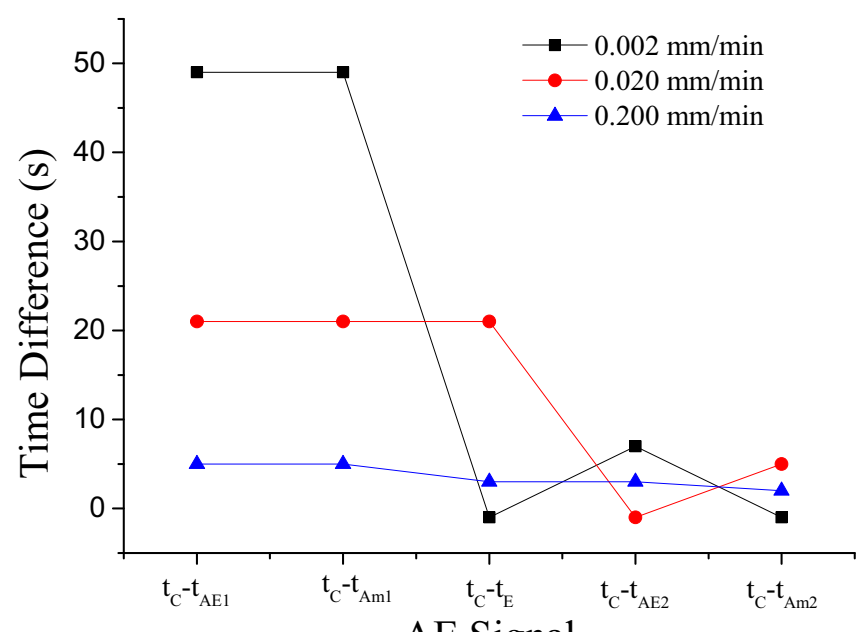

AE Signal

Fig. 9. Relationship between the acoustic emission signal peak time and specimen fracture time.

prevention is more important than failure identification. Therefore, according to the data presented in Fig. 9, the first AE signal peak would be more appropriate for reflecting rock failure in practical applications.

As shown in Table 3, the differences between the shear displacements of the two AE count rate and amplitude peaks were small. The grain size distribution of the sandstone samples ranged from 0.1 to $0.5 \mathrm{~mm}$. When the displacement rate was $0.002 \mathrm{~mm} / \mathrm{min}$, the ratios between the shear displacements of the different acoustic emission signal peaks and their particle diameters ranged from $0.2 \sim 1.7 \%$. As the displacement rate increased, these ratios 
Table 3

Shear displacement values of the acoustic emission signal peaks

\begin{tabular}{|c|c|c|c|c|c|c|}
\hline $\begin{array}{c}V \\
{[\mathrm{~mm} / \mathrm{min}]}\end{array}$ & $\begin{array}{c}t_{\mathrm{AE} 1} \\
{[\mathrm{~s}]}\end{array}$ & $\begin{array}{c}t_{\mathrm{AE} 2} \\
{[\mathrm{~s}]}\end{array}$ & $\begin{array}{c}\Delta s_{\mathrm{AE}} \\
{[\mathrm{mm}]}\end{array}$ & $\begin{array}{c}t_{\mathrm{Am} 1} \\
{[\mathrm{~s}]}\end{array}$ & $\begin{array}{c}t_{\mathrm{Am} 2} \\
{[\mathrm{~s}]}\end{array}$ & $\begin{array}{c}\Delta s_{\mathrm{Am}} \\
{[\mathrm{mm}]}\end{array}$ \\
\hline 0.002 & 14352 & 14394 & 0.0014 & 14352 & 14402 & 0.0017 \\
0.020 & 1342 & 1364 & 0.0073 & 1342 & 1358 & 0.0053 \\
0.200 & 102 & 104 & 0.0067 & 102 & 105 & 0.0100 \\
\hline
\end{tabular}

Notes: $t_{\mathrm{AE} 1}$ denotes the first $\mathrm{AE}$ count rate peak, $t_{\mathrm{AE} 2}$ denotes the second $\mathrm{AE}$ count rate peak, $\Delta s_{\mathrm{AE}}$ denotes the difference between the shear displacement values of the two $\mathrm{AE}$ count rate peaks, $t_{\mathrm{Am} 1}$ denotes the first amplitude peak, $t_{\mathrm{Am} 2}$ denotes the second amplitude peak, and $\Delta s_{\text {Am }}$ denotes the difference between the shear displacement values of the two amplitude peaks.

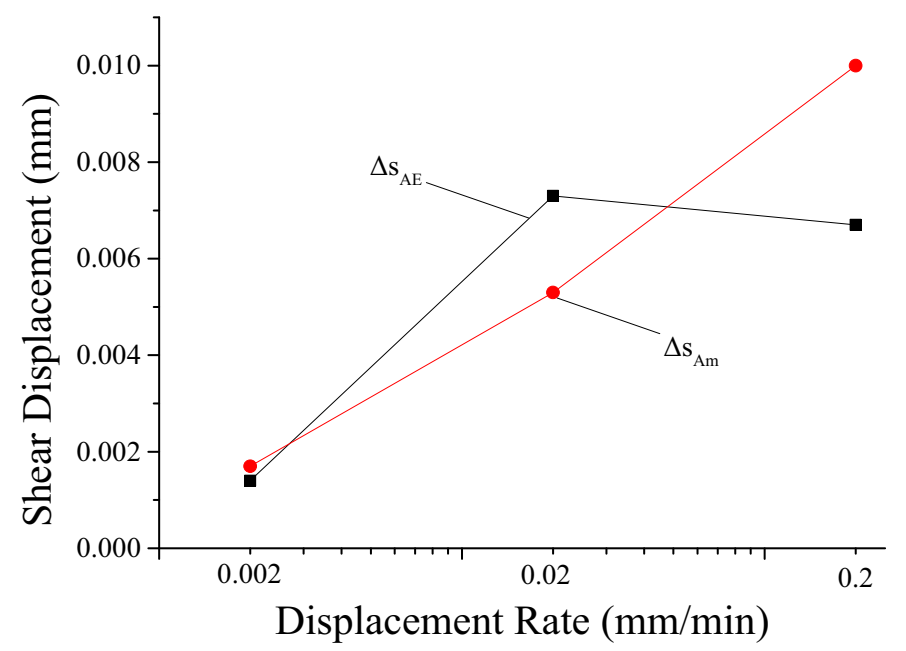

Fig. 10. Shear displacement values of the acoustic emission signal peaks.

also increased. According to Fig. 10 and the stress propagation mechanism (Havaej et al. 2013), the acoustic emission signal of the first peak in sandstone results from the propagation and coalescence of cracks, which cause slight deformations. These deformations result in instantaneous reductions in shear stress. As the shear displacement increased, the isolated cracked formed larger fractures, eventually resulting in rupture. The difference between the shear displacements of the two amplitude peaks also increased linearly as the displacement rate increased. 


\section{CONCLUSIONS}

In this paper, acoustic emission signals were used to effectively monitor the shear behaviors of sandstone specimens under different displacement rates. Direct shear tests were conducted in order to investigate the acoustic emission characteristics of the sandstone under various shear loading conditions. The results indicated that $\mathrm{AE}$ signals could be applied to the real-time monitoring and reflection of sandstone rock failure.

The shear stress of the sandstone specimens decreased significantly in a relatively short amount of time during shear failure. These changes were reflected by the AE count rates and amplitude curves of the specimens. The AE signals corresponded with the amount of shear stress under various displacement rates. In addition, as the displacement increased, the amount of cumulative damage to each specimen decreased, and the AE energy peaks became larger and occurred earlier in time. The cumulative AE count primarily increased during the post-peak period. This indicated that higher displacement rates were associated with larger cracks in the samples (Kranz 1979). In contrast, lower displacement rates were primarily associated with the initiation and propagation of micro-cracks.

According to the comprehensive analysis of the AE signals, the time at which the second peak in amplitude occurred corresponded closely with the time of fracture. Thus, count rate peaks and initial peaks in amplitude could be a reference in practical engineering applications to provide warnings regarding rock failure.

Acknowledgments. The authors would like to thank the General Project of the National Natural Science Foundation of China (51474040, 51434003) for their financial support.

\section{References}

Chang, S.H., and C.I. Lee (2004), Estimation of cracking and damage mechanisms in rock under triaxial compression by moment tensor analysis of acoustic emission, Int. J. Rock Mech. Mining Sci. 41, 7, 1069-1086, DOI: 10.1016/ j.ijrmms.2004.04.006.

Goszczyńska, B., G. Świt, W. Trąmpczyński, A. Krampikowska, J. Tworzewska, and P. Tworzewski (2012), Experimental validation of concrete crack identification and location with acoustic emission method, Arch. Civil Mech. Eng. 12, 1, 23-28, DOI: 10.1016/j.acme.2012.03.004. 
Havaej, M., A. Wolter, D. Stead, Z. Tuckey, L. Lorig, and E. Eberhardt (2013), Incorporating brittle fracture into three-dimensional modelling of rock slopes. In: Proc. Int. Symp. Slope Stab., Brisbane, Australia.

Katsuyama, K. (1996), Application of AE Techniques, Metallurgy Industry Press, Bejing.

Kawamato, T., and T. Saito (1974), The behaviour of rock like materials in some controlled strain rates. In: III Congress ISRM, Denver, USA, Vol. 2, 161166.

Kranz, R.L. (1979), Crack growth and development during creep of Barre granite, Int. J. Rock Mech. Mining Sci. Geomech. Abstr. 16, 1, 23-35, DOI: 10.1016/0148-9062(79)90772-1.

Lajtai, E.Z., E.J.S. Duncan, and B.J. Carter (1991), The effect of strain rate on rock strength, Rock Mech. Rock Eng. 24, 2, 99-109, DOI: 10.1007/BF01032501.

Lavrov, A. (2001), Kaiser effect observation in brittle rock cyclically loaded with different loading rates, Mech. Mater. 33, 11, 669-677, DOI: 10.1016/ S0167-6636(01)00081-3.

Li, Y.H., J.P. Liu, X.D. Zhao, and Y.J. Yang (2010), Experimental studies of the change of spatial correlation length of acoustic emission events during rock fracture process, Int. J. Rock Mech. Min. Sci. 47, 8, 1254-1262, DOI: 10.1016/j.ijrmms.2010.08.002.

Lockner, D. (1993), The role of acoustic emission in the study of rock fracture, Int. J. Rock Mech. Min Sci. Geomech. Abstr. 30, 7, 883-899, DOI: 10.1016/ 0148-9062(93)90041-B.

Majewska, Z., and Z. Mortimer (2006), Chaotic behaviour of acoustic emission induced in hard coal by gas sorption-desorption, Acta Geophys. 54, 1, 5059, DOI: 10.2478/s11600-006-0005-z.

Moradian, Z.A., G. Ballivy, P. Rivard, C. Gravel, and B. Rousseau (2010), Evaluating damage during shear tests of rock joints using acoustic emissions, Int. J. Rock Mech. Min. Sci. 47, 4, 590-598, DOI: 10.1016/ j.ijrmms.2010.01.004.

Rao, M.V.M.S., and K. Kusunose (1995), Failure zone development in andesite as observed from acoustic emission locations and velocity changes, Phys. Earth Planet Int. 88, 2, 131-143, DOI: 10.1016/0031-9201(94)02967-G.

Ray, S.K., M. Sarkar, and T.N. Singh (1999), Effect of cyclic loading and strain rate on the mechanical behaviour of sandstone, Int. J. Rock Mech. Min. Sci. 36, 4, 543-549.

Stock, G.M., S.J. Martel, B.D. Collins, and E.L. Harp (2012), Progressive failure of sheeted rock slopes: the 2009-2010 Rhombus Wall rock falls in Yosemite Valley, California, USA, Earth Surf. Proc. Landforms 37, 5, 546-561, DOI: 10.1002/esp.3192. 
Taheri, A., and K. Tani (2010), Assessment of the stability of rock slopes by the slope stability rating classification system, Rock Mech. Rock Eng. 43, 3, 321-333, DOI: 10.1007/s00603-009-0050-4.

Xu, J., S. Li, Y. Tao, X. Tang, and X. Wu (2009), Acoustic emission characteristic during rock fatigue damage and failure, Proc. Earth Planet. Sci. 1, 1, 556559, DOI: 10.1016/j.proeps.2009.09.088.

Xu, J., S. Peng, G. Yin, H. Yang, and W. Wang (2011), Development of mesoshear test equipment for coal rock containing gas and its application, Chin. J. Rock Mech. Eng. 30, 4, 677-685.

Yang, S.Q., and H.W. Jing, and S.Y. Wang (2012), Experimental investigation on the strength, deformability, failure behavior and acoustic emission locations of red sandstone under triaxial compression, Rock Mech. Rock Eng. 45, 4, 583-606, DOI: 10.1007/s00603-011-0208-8.

Zhao, X., Y. Li, R. Yuan, T. Yang, J. Zhang, and J. Liu (2007), Study on crack dynamic propagation process of rock samples based on acoustic emission location, Chin. J. Rock Mech. Eng. 26, 5, 944-950.

Zhurkov, S.N. (1965), Kinetic concept of the strength of solids, Int. J. Fract. 4, 311 323.

Received 25 November 2015

Received in revised form 12 April 2016

Accepted 5 May 2016 